\title{
유전함수를 이용한 $\mathrm{ZnO}-\mathrm{Bi}_{2} \mathrm{O}_{3}-\mathrm{Cr}_{2} \mathrm{O}_{3}$ 바리스터의 a.c. 특성 분석
}

\author{
홍연우 ${ }^{1, a}$, 신효순 ${ }^{1}$, 여동훈 $^{1}$, 김진호 $^{2}$ \\ 1 한국세라믹기술원 바이오IT융합센터 \\ 2 경북대학교 신소재공학부
}

\section{Analysis of a.c. Characteristics in $\mathrm{ZnO}-\mathrm{Bi}_{2} \mathrm{O}_{3}-\mathrm{Cr}_{2} \mathrm{O}_{3}$ Varistor using Dielectric Functions}

\author{
Youn-Woo Hong ${ }^{1, a}$, Hyo-Soon Shin ${ }^{1}$, Dong-Hun Yeo ${ }^{1}$, and Jin-Ho Kim ${ }^{2}$ \\ ${ }^{1}$ Bio-IT Convergence Center, Korea Institute of Ceramic Engineering and Technology, Seoul 153-801, Korea \\ ${ }^{2}$ School of Materials Science and Engineering, Kyungpook National University, Daegu 702-701, Korea
}

(Received February 16, 2010; Revised April 6, 2010; Accepted April 15, 2010)

\begin{abstract}
In this study, we have investigated the effects of $\mathrm{Cr}$ dopant on the bulk trap levels and grain boundary characteristics of $\mathrm{Bi}_{2} \mathrm{O}_{3}$-based $\mathrm{ZnO}(\mathrm{ZB})$ varistor using admittance spectroscopy and dielectric functions (such as $Z^{*}, \mathrm{Y}^{*}, \mathrm{M}^{*}, \varepsilon^{*}$, and $\tan \delta$ ). Admittance spectra show more than two bulk traps of $\mathrm{Zn}_{\mathrm{i}}$ and $\mathrm{V}_{\mathrm{o}}$ probably in different ionization states in $\mathrm{ZnO}-\mathrm{Bi}_{2} \mathrm{O}_{3}-\mathrm{Cr}_{2} \mathrm{O}_{3}$ (ZBCr) system. Three kinds of temperature-dependant activation energies ( $\mathrm{E}_{\mathrm{bt}}{ }^{\prime} \mathrm{s}$ ) were calculated as $0.11 \sim 0.14 \mathrm{eV}$ of attractive coulombic center, $0.16 \sim 0.17 \mathrm{eV}$ of $Z n_{i}^{*}$, and $0.33 \mathrm{eV}$ of $V_{o}^{*}$ as dominant bulk defects. The grain boundaries of $\mathrm{ZBCr}$ could be electrochemically divided into two types as a sensitive to ambient oxygen i.e. electrically active one and an oxygen-insensitive i.e. electrically inactive one. The grain boundaries were electrically single type under $460 \mathrm{~K}$ (equivalent circuit as parallel $\left.\mathrm{R}_{\mathrm{gbl}} \mathrm{C}_{\mathrm{gb} 1}\right)$ but separated as double one $\left(\mathrm{R}_{\mathrm{gb} 1} \mathrm{C}_{\mathrm{gb} 1}-\mathrm{R}_{\mathrm{gb} 2} \mathrm{C}_{\mathrm{gb} 2}\right)$ over $480 \mathrm{~K}$. It is revealed that the dielectric functions are very useful tool to separate the overlapped bulk defect levels and to characterize the electrical properties of grain boundaries.
\end{abstract}

Keywords: $\mathrm{ZnO}$ varistor, $\mathrm{Bi}_{2} \mathrm{O}_{3}, \mathrm{Cr}_{2} \mathrm{O}_{3}$, Dielectric functions, a.c. characteristics

\section{1. 서 론}

$\mathrm{ZnO}$ 바리스터는 일반적으로 디스크형(disk type)과 적층칩형(chip type)의 다양한 제품으로 제조되어 전 력계통과 전자기기의 회로 등을 과전압 및 각종 써지 (surge)로부터 보호하는 소자로 폭 넓게 사용되는 전 자 세라믹스 부품이다 [1-3]. $\mathrm{ZnO}$ 바리스터에서 $\mathrm{Bi}^{-}$ 계 $\mathrm{ZnO}$ 바리스터는 입내와 입계특성이 첨가되는 도 펀트(dopant)에 따라 크게 변하는데 그 중 $\mathrm{Cr}_{2} \mathrm{O}_{3}$ 의 첨가는 다양한 입계 $\mathrm{Bi}$-rich상을 형성하기 때문에 입

a. Corresponding author; hyw-kea@kicet.re.kr
계에 생성된 상의 조성에 따라 특별히 분석하기 어려 운 계로 알려져 있다 [2-5]. $\mathrm{ZnO}$ 바리스터의 결함화 학과 관련하여 발표된 결함 준위는 일반적으로 $\mathrm{Zn}_{\mathrm{i}}$ 와 $\mathrm{V}_{\text {o }}$ 이 대표적이다 [6,7]. 또한 $\mathrm{ZnO}$ 바리스터에서 확인 되는 다양한 계면 상태 준위는 크게 두 부류로 구분할 수 있다. 이들은 $\mathrm{ZnO} / \mathrm{ZnO}$ 의 동종접합 계면과 $\mathrm{ZnO}-\mathrm{Bi}^{-}$ rich 상- $\mathrm{ZnO}$ 의 이종접합 계면으로서, 전자는 전기적 으로 활성이므로 전류-전압의 비선형성을 나타내고, 후자는 전기적으로 비활성으로 누설 전류와 관계된다 $[3,8,9]$. 전자세라믹 재료에 대하여 다양한 유전 함수 들을 함께 사용하게 되면 측정 주파수 대역과 측정 
온도 범위에 따라서 재료의 입내 및 입계 특성을 전 체적으로 확인할 수 있는 좋은 방법으로 알려져 있다 [8,10,11]. 특별히 $\mathrm{ZnO}$ 바리스터에서 $\mathrm{Cr}$ 을 첨가한 계 에 대한 전기적 특성 중 유전함수를 사용하여 결함과 입계 특성을 종합적으로 분석하여 발표한 내용은 거 의 없는 실정이다. 따라서 본 연구에서는 $\mathrm{ZnO}-$ $\mathrm{Bi}_{2} \mathrm{O}_{3}-\mathrm{Cr}_{2} \mathrm{O}_{3}(\mathrm{ZBCr})$ 의 3 성분계에 대하여 각종 유전함 수(dielectric functions : $Z^{*}, \mathrm{Y}^{*}, \mathrm{M}^{*}, \varepsilon^{*}, \tan \delta$ )를 이용 하여 $\mathrm{ZnO}$ 바리스터의 입내 및 입계 특성에 미치는 $\mathrm{Cr}_{2} \mathrm{O}_{3}$ 의 영향에 대하여 $78 \sim 780 \mathrm{~K}$ 온도 구간에서 조 사하였다.

\section{2. 실 험}

본 실험에서 사용한 원료 분체는 특급 시약(순도 $99.9 \%$, 고순도 화학, 일본)의 $\mathrm{ZnO}, \mathrm{Bi}_{2} \mathrm{O}_{3}(1.0 \mathrm{~mol} \%)$, $\mathrm{Cr}_{2} \mathrm{O}_{3} \quad(0.5 \mathrm{~mol} \%)$ 으로서 일반적인 세라믹 공정으로 혼합하여 출발 원료로 사용하였다. 이때 볼:슬러리 및 원료분체:에탄올의 부피비는 각각 $6: 4,1: 12$ 로 하였다. 성형체는 출발 원료를 $10 \mathrm{~mm} \phi$ 의 원통형 금형에 장 입하여 먼저 $25 \mathrm{MPa}$ 로 1축 가압 성형한 후 $98 \mathrm{MPa}$ 로 정수합 처리하여 제조하였다. 성형 시편은 $1300^{\circ} \mathrm{C}$ 에서 1 시간 공기 중에서 소결하였으며, 승온 및 냉 각 속도는 $5^{\circ} \mathrm{C} / \mathrm{min}$.로 고정하였다. 소결 시편은 약 $1.0 \mathrm{~mm}$ 두께로 하여 양면에 $\mathrm{Ag}$ 전극(ohmic contact 용)을 직경이 $6 \mathrm{~mm} \phi$ 가 되게 실크 스크린으로 도포 하여 소성로에 넣고 $600{ }^{\circ} \mathrm{C}$ 에서 10 분 열처리하여 측정 용 시편으로 준비하였다.

먼저 $\mathrm{Cr}$ 을 첨가한 $\mathrm{ZB}$ 계의 입내 특성 즉, 결함(또는 트랩)준위를 조사하기 위하여 admittance spectroscopy (zero dc bias)를 사용하였다 [7]. 각 결함 준위의 고 유 완화시간 $\left(\tau_{n}\right)$ 은 다음과 같이 주어진다.

$$
\tau_{n}=\frac{e}{2 g A^{*} T^{2} \sigma_{n}} \exp \left(\frac{E_{b t}}{k T}\right)
$$

여기서 $\mathrm{E}_{\mathrm{bt}}=$ 도너트랩과 전도대 하단의 에너지 차 $[\mathrm{eV}], \sigma_{\mathrm{n}}=$ 포획단면적 $\left[\mathrm{cm}^{2}\right], \mathrm{g}=$ 트랩준위의 축퇴도 의 역수 $(=0.5), \mathrm{A}^{*}=$ 유효 Richardson 정수 $(\sim 30$ $\left.\left[\mathrm{A} /\left(\mathrm{cm}^{2} \mathrm{~K}^{2}\right)\right]\right), \mathrm{T}=$ 절 대온도 $[\mathrm{K}], e=$ 전자 전하량, $k$ $=$ Boltzmann상수이다. 여기서 $\ln \left(\omega / \mathrm{T}^{2}\right)$ vs. $1 / \mathrm{T}$ 에서 그 기울기 $\left(=-\mathrm{E}_{\mathrm{bt}} / k\right)$ 로부터 $\mathrm{E}_{\mathrm{bt}}$ 를 구하고, 절편 $\ln \left(2 \mathrm{gA}^{*} \sigma_{\mathrm{n}} / e\right)$ 로부터 $\sigma_{\mathrm{n}}$ 을 구하였다. 이를 위한 측정에 는 HP4194A를 이용하여 $78 \sim 350 \mathrm{~K}$ 까지 $1.0 \mathrm{~K} / \mathrm{min}$ 의 속도로 승온하면서 $2 \mathrm{~K}$ 간격으로 7 개의 특정 주파수 $(10 \sim 100 \mathrm{kHz})$ 를 정하여 각각의 conductance를 측정 하였다.

$\mathrm{ZBCr}$ 의 주파수 응답 특성은 다음과 같은 각종 유 전함수(dielectric functions)를 이용하여 조사하였다 $[8,9,11]$.

$$
\begin{aligned}
& Y^{*}=Z^{*-1}=j \omega C_{0} \varepsilon^{*}=G+j \omega C=Y^{\prime}+j Y^{\prime \prime} \\
& Z^{*}=Y^{*-1}=\left[j \omega C_{0} \varepsilon^{*}\right]^{-1}=Z^{\prime}+j Z^{\prime \prime} \\
& M^{*}=\varepsilon^{*-1}=j \omega C_{0} Z^{*}=M^{\prime}+j M^{\prime \prime} \\
& \varepsilon^{*}=M^{*-1}=\left[j \omega C_{0} Z^{*}\right]^{-1}=Y^{*}\left[j \omega C_{0}\right]^{-1}=\varepsilon^{\prime}-j \varepsilon^{\prime \prime} \\
& \tan \delta=\varepsilon^{\prime \prime} / \varepsilon^{\prime}=M^{\prime \prime} / M^{\prime}=Z^{\prime} / Z^{\prime \prime}=Y^{\prime} / Y^{\prime \prime}
\end{aligned}
$$

여기서, $\omega=$ 각주파수 $(=2 \pi \mathrm{f}, \mathrm{f}=$ 주파수 $), \mathrm{C}_{0}=\varepsilon_{0} \cdot \mathrm{A} / \mathrm{t}$ ( $\varepsilon_{0}=$ 진공유전율, $\mathrm{A}=$ 단면적, $\mathrm{t}=$ 시편두께 $), \mathrm{j}=\sqrt{-1}$ 이다.

먼저 상온 이하에서의 재료의 입내 특성에 관한 정 보를 식 (4) (6)의 주파수 및 온도 의존성을 조사하 여 얻었으며, 상온 이상의 온도 범위에서는 식 (3)과 (4)를 이용하여 동일한 방법으로 입계 특성에 대한 정보를 얻었다. 유전함수 특성 분석을 위하여 $\mathrm{HP} 4194 \mathrm{~A}$ 를 이용하여 주파수는 $100 \mathrm{~Hz} \sim 15 \mathrm{MHz}$ 대역에서, 측정온도는 $78 \sim 780 \mathrm{~K}$ 범위에서 각 유전 함수 별로 복소 평면도(complex plane plot) 또는 주파수 응답도 (frequency explicit plot)를 이용하여 각 피크의 최대 값에 대한 $\mathrm{T}_{\mathrm{p}}$ 와 $\mathrm{f}_{\max }$ 를 구하고, 특히 임피던스 (impedance)와 모듈러스(modulus) 데이터에서 $Z^{\prime \prime}{ }_{\text {max }}$ 와 $\mathrm{M}^{\prime \prime}{ }_{\max }$ 를 그래프 상에서 구하여 식 (7)을 이용하여 입계 저항 $\left(\mathrm{R}_{\mathrm{gb}}\right)$ 과 정전용량 $\left(\mathrm{C}_{\mathrm{gb}}\right)$ 을 추출하였다 [9-11].

$$
Z_{\max }^{\prime \prime}=\frac{R}{2}, \quad M_{\max }^{\prime \prime}=\frac{C_{0}}{2 C}
$$

이렇게 구한 $\mathrm{T}_{\mathrm{p}}$ 와 $\tau^{-1}=\omega_{\max }=2 \pi \mathrm{f}_{\max }, Z^{\prime \prime}{ }_{\text {max }}, \mathrm{M}^{\prime \prime}{ }_{\text {max }}$ 값은 아레니우스(Arrehnius)식 $\left(\tau=\tau_{0} \exp \left(E_{a} / k T\right), \rho=\rho_{0} \exp \left(E_{a} / k T\right)\right.$, $\tau=$ 완화시간, $\rho=$ 비저항 $[\Omega \mathrm{cm}], \mathrm{E}_{\mathrm{a}}=\tau$ 혹은 $\rho$ 에 대 한 활성화 에너지, $k$ : 볼쯔만 상수 $\left(8.62 \times 10^{-5} \mathrm{eV} / \mathrm{K}\right)$, $\mathrm{T}=[\mathrm{K}])$ 을 이용하여 각각 $\ln \tau$ vs. $1 / \mathrm{T}$ 및 $\ln \rho$ vs. 


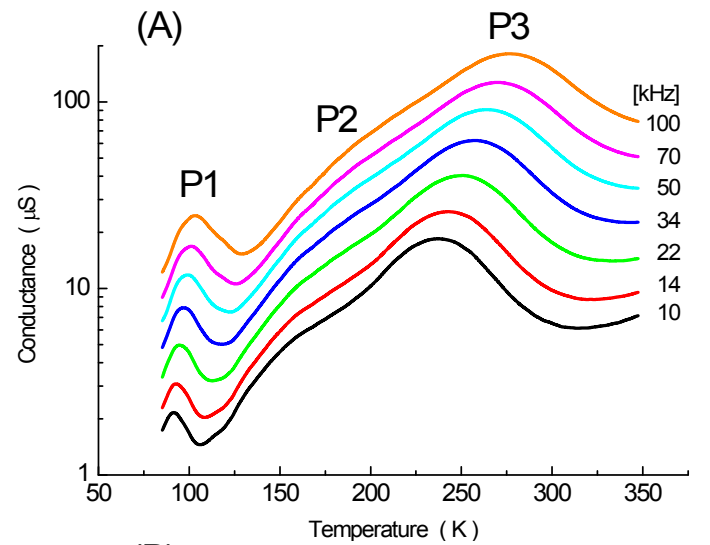

(B)

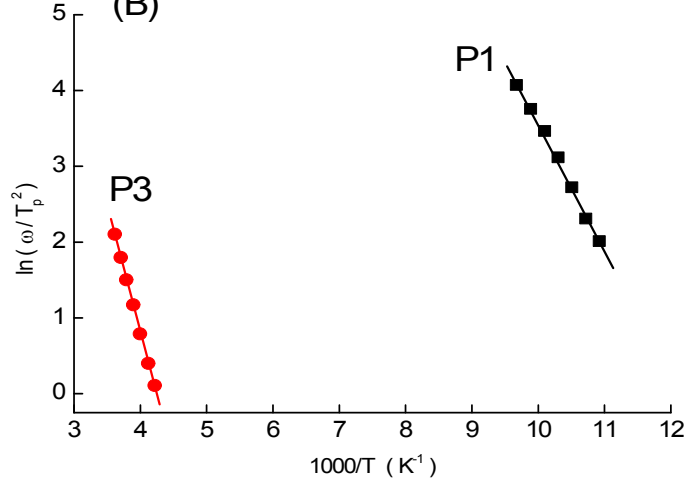

Fig. 1. (A) admittance spectra according to frequency and temperature, (B) $\ln \left(\omega / T_{p}^{2}\right)$ vs. $1000 / \mathrm{T}$.

$1 / \mathrm{T}$ plot을 통하여 그 기울기로부터 상온 이하의 값 에서는 결함 준위(혹은 이온화 에너지, $\mathrm{E}_{\mathrm{bt}}$ )와 상온 이상에서는 계면(입계) 활성화 에너지 $\left(\mathrm{E}_{\mathrm{a}}\right)$ 를 구하는데 사용하였다 [9,11].

\section{3. 결과 및 고찰}

\subsection{Admittance Spectroscopy (AS)}

그림 1은 (A) 78 350 K의 온도 구간에서 7개의 주파수에 대한 admittance spectra를, (B) 피크의 온 도와 주파수를 이용하여 $\ln \left(\omega / T_{p}^{2}\right)$ vs. 1000/T를 나타 낸 것이다.

그림 $1(\mathrm{~A})$ 와 같이 주어진 주파수/온도에서 conductance 는 P1과 P3에서 피크값을 나타내었다. P2는 독립된 피크값으로 나타나지 않고 다소 폭넓게 나타났다. 식 (1)를 적용하여 그림 $1(\mathrm{~B})$ 의 그래프로부터 계산된 P1 과 $\mathrm{P} 3$ 각각의 결함 준위 즉, 벌크 크랩 준위 혹은 이
온화 에너지 $\left(\mathrm{E}_{\mathrm{bt}}\right)$ 는 $0.14 \mathrm{eV}$ 와 $0.29 \mathrm{eV}$ 로 나타났으며, 각각에 대한 포획 단면적은 $3.4 \times 10^{-12} \mathrm{~cm}^{2}$ 과 $7.4 \times 10^{-15}$ $\mathrm{cm}^{2}$ 로 계산되었다. $\mathrm{P} 1$ 결함 준위는 $\mathrm{ZnO}$ 바리스터에 서도 보고되는 바와 같은 준위로 장범위 쿨롱인력 전 위를 가진 결함 중심으로 보이며 [7,11], P3 준위는 일반적으로 알려진 산소공공 $\left(V_{o}^{*}\right)$ 이 갖는 $0.32 \mathrm{eV}$ 보다 낮고 $Z n_{i}^{*}(0.20 \mathrm{eV})$ 보다 높은 새로운 결함 중심으로 보이지만, 산소공공의 결함으로 확인된다 [6,11]. 이는 본 실험의 주파수 영역 $(10 \sim 100 \mathrm{kHz})$ 과 온도 범위 $(150 \sim 220 \mathrm{~K})$ 에서는 $Z n_{i} \cdot$ 에 의한 피크가 나타날 수 있 는데 그 강도가 약하여 그래프 상으로는 $\mathrm{P} 2$ 로 발견되 며 뚜렷한 피크를 형성하지 않고 단순히 $V_{o}^{\circ}$ 이 갖는 피크에 영향을 주어 P3 준위의 이온화 에너지가 0.29 $\mathrm{eV}$ 로 계산된 것으로 사료된다. 이에 대한 보다 자세 한 분석을 위하여 각종 유전함수를 적용하여 보았다.

\section{2 유전함수를 이용한 결함(defect) 분석}

그림 2 는 주파수와 온도에 따른 각종 유전함수에 대한 특성을 (A) $85 \mathrm{~K}$ 와 (B) $220 \mathrm{~K}$ 의 값을 나타내었 으며, $(\mathrm{C})$ 는 $\tan \delta$ 값에 대한 일부 측정온도 $(85 \mathrm{~K}, 180$ $\sim 200 \mathrm{~K})$ 에서의 주파수 응답 특성을 나타낸 것이다. 그림 $2(\mathrm{D})$ 는 아레니우스(Arrehnius)식 $\left(\tau=\tau_{0} \exp \left(E_{a} / k T\right)\right)$ 을 이용하여 그래프로 도시한 것이다. 또한 표 1에는 그림 2에서 추출한 결함 준위를 요약한 것으로 $\mathrm{AS}$ 에 서 구한 결함 준위를 비교를 목적으로 함께 제시하 였다. 그림 $2(\mathrm{~A})$ 와 $(\mathrm{B})$ 는 각각 $85 \mathrm{~K}$ 와 $220 \mathrm{~K}$ 에서의 각 유전함수의 주파수 응답도를 나타낸 것으로 $\mathrm{P} 1$ 은 $\varepsilon^{\prime \prime}-\log f$ 와 $\tan \delta-\log f$ 에서만 나타나고, $\mathrm{P} 2$ 는 $\tan \delta-\log f$ 와 $\mathrm{M}^{\prime \prime}-\log$ 에서, $\mathrm{P} 3$ 는 다시 $\varepsilon^{\prime \prime}-\log$ 와 $\tan \delta-\log f$ 에서 명확하게 나타났다. 모든 피크는 $\tan \delta-\log f$ 에서 보다 명확하게 확인 가능하였다. 따라서 $\mathrm{P} 1, \mathrm{P} 2, \mathrm{P} 3$ 피크는 사용하는 각 유전함수에 따라서 명확히 구별되게 나 타날 수도 있지만 그렇지 않을 수도 있음을 확인할 수 있다. 뿐만 아니라 각 유전함수에서 나타나는 피 크의 위치는 $\tau_{\varepsilon^{\prime \prime}} \geq \tau_{Y^{\prime \prime}}>\tau_{\tan \delta}>\tau_{Z^{\prime \prime}} \geq \tau_{M^{\prime \prime}}$ 의 순서로 특정 결함에 대응해서 나타나게 된다 [11]. 그림 2와 같이 각 유전함수에 의한 $\mathrm{P} 1$ 결함 준위는 $0.14 \mathrm{eV}(\mathrm{AS})$, $0.12 \mathrm{eV}(\tan \delta-\log f), 0.11 \mathrm{eV}\left(\varepsilon^{\prime \prime}-\log \mathrm{f}\right)$ 로 각 유전함 수에 대하여 다소 차이를 보이며 피크가 나타나는 온 도 영역과 포획 단면적으로 판단할 때 장범위 쿨롱인 력에 의한 결함으로 할당할 수 있겠다 [11]. P2는 $0.16 \mathrm{eV}(\tan \delta-\log )$ 와 $0.17 \mathrm{eV}\left(\mathrm{M}^{\prime \prime}-\log \right)$ 로 $Z n_{i}^{*}$ 로 할 당할 수 있지만 그 이온화 에너지가 기존의 발표보다 

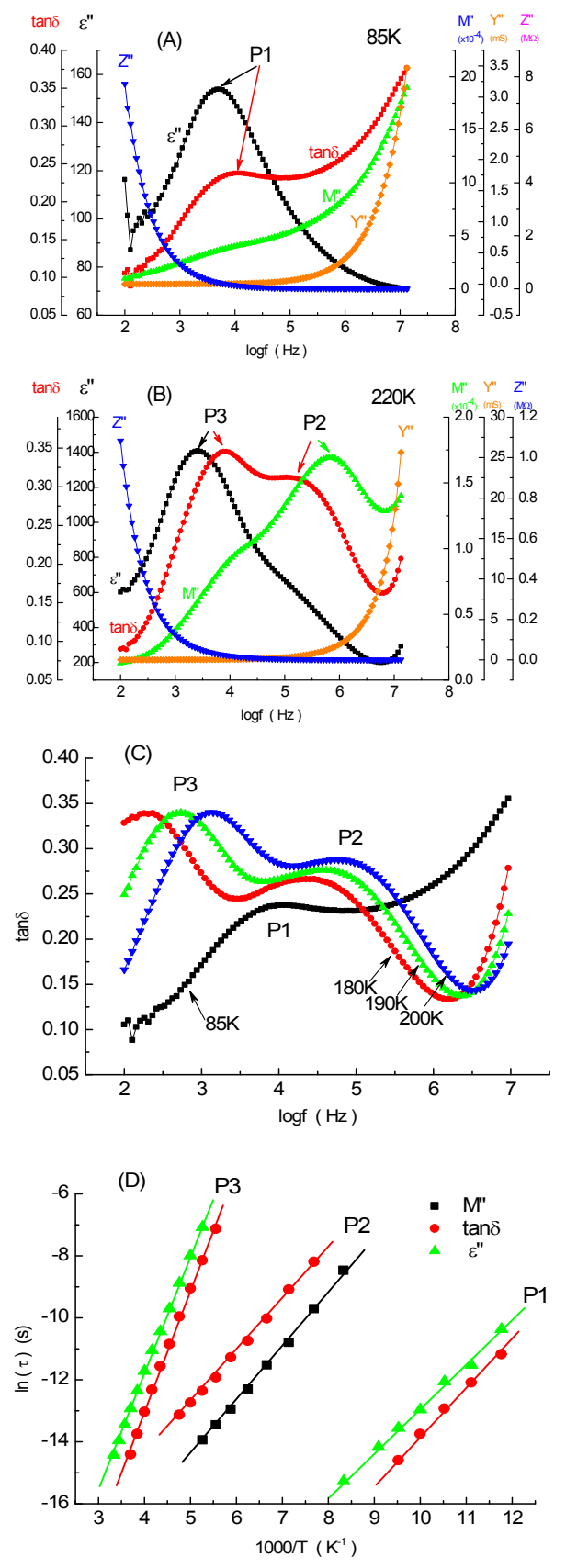

Fig. 2. Characteristics of each dielectric functions by frequency and temperature. (A) $110 \mathrm{~K}$, (B) $220 \mathrm{~K}$, (C) $\tan \delta-\log f-T$, (D) $\ln \tau$ vs. $1000 / \mathrm{T}$.

다소 낮게 나타났다 [6,7,11]. P3는 $0.29 \mathrm{eV}$ (AS), $0.33 \mathrm{eV}(\tan \delta-\log f), 0.33 \mathrm{eV}\left(\varepsilon^{\prime \prime}-\log f\right)$ 로 다소 차이 를 나타내었는데 일반적으로 $\mathrm{ZnO}$ 바리스터에서 발견 되는 $V_{o}$ 로 할당할 수 있다 $[6,10,11]$.
Table 1. Summary of defect levels of ZBCr.

\begin{tabular}{llll}
\hline Method & P1 $(\mathrm{eV})$ & P2 $(\mathrm{eV})$ & P3 $(\mathrm{eV})$ \\
\hline AS & 0.14 & - & 0.29 \\
$\mathrm{M}^{\prime \prime}-\log \mathrm{f}$ & - & 0.16 & - \\
$\tan \delta-\operatorname{logf}$ & 0.12 & 0.17 & 0.33 \\
$\varepsilon^{\prime \prime}-\log \mathrm{f}$ & 0.11 & - & 0.33 \\
\hline
\end{tabular}

\section{3 입계 특성 분석}

유전함수 중 특별히 상온 이상의 온도에서 적용하는 $Z^{*}$ 와 $\mathrm{M}^{*}$ 은 impedance and modulus spectroscopy (IS $\& \mathrm{MS}$ )로 알려져 있으며, 입계의 활성화 에너지와 저 항 및 정전용량 성분을 분석할 수 있을 뿐 아니라 입 계의 온도 안정성이나 입계 전위 장벽의 균일성까지 분석할 수 있는 것으로 알려져 있다 [9,10]. 그림 3에는 $\mathrm{ZBCr}$ 시편에 대하여 (A) $Z^{\prime \prime}-, \mathrm{M}^{\prime \prime}-\operatorname{logf}(420 \mathrm{~K}),(\mathrm{B})$ $Z^{\prime \prime}-, \mathrm{M}^{\prime \prime}-\operatorname{logf}(520 \mathrm{~K}),(\mathrm{C}) \mathrm{M}^{\prime \prime}-\operatorname{logf}(360 \sim 580 \mathrm{~K})$, (D) 입계 저항 $\left(\mathrm{R}_{\mathrm{gb}}\right)$ 및 입계 정전용량 $\left(\mathrm{C}_{\mathrm{gb}}\right),(\mathrm{E}) \ln \mathrm{n}$, $\ln \tau$ vs. 1000/T plot을 나타내었다. 또한 그림 3(A)와 (B)에는 측정한 데이터에 기초하여 식 (7)을 이용하 여 각 온도에서 등가회로와 그 값을 함께 제시하였 다. 그림 $3(\mathrm{~A}) \sim(\mathrm{C})$ 에서 보듯이 $\mathrm{ZBCr}$ 계의 입계는 약 $460 \mathrm{~K}$ 이하에서는 단일 입계로 존재하다가 $480 \mathrm{~K}$ 이 상에서는 이중 입계로 분리되는 것을 알 수 있다. 먼 저 단일 입계가 갖는 입계 활성화 에너지 $\left(\mathrm{E}_{\mathrm{gb1}}\right)$ 는 $0.67 \mathrm{eV}$ 로 그림 $3(\mathrm{E})$ 의 기울기 $\mathrm{a}$ 와 $\mathrm{a}^{\prime}$ 으로 확인할 수 있다. 그리고 분리된 피크에 해당하는 입계 활성화 에너지 $\left(\mathrm{E}_{\mathrm{gb} 1}, \mathrm{E}_{\mathrm{gb} 2}\right)$ 는 각각 $1.22 \sim 1.23 \mathrm{eV}, 1.20 \sim 1.22$ $\mathrm{eV}$ 로 계산되었으며, 그림 $3(\mathrm{E})$ 의 기울기 $\mathrm{b}$ 와 $\mathrm{b}^{\prime}\left(\mathrm{E}_{\mathrm{gb} 2}\right)$ 및 $\mathrm{c}$ 와 $\mathrm{c}^{\prime}\left(\mathrm{E}_{\mathrm{gbl}}\right)$ 으로 확인할 수 있다. 따라서 $\mathrm{Cr}$ 이 첨 가된 $\mathrm{ZB}$ 계는 $460 \mathrm{~K}$ 이하에서는 $0.67 \mathrm{eV}$ 의 낮은 입계 활성화 에너지를 갖다가 온도가 높아지면 두 개의 입 계로 분리(g.b.1과 g.b.2 그림 3(C) 참고)되지만 그 값 은 $1.2 \mathrm{eV}$ 로 거의 동일한 입계 활성화 에너지를 갖는 것을 확인 할 수 있다.

또한 400 780 K 구간에서 측정한 IS \& MS 결과 를 토대로 입계 저항 $\left(\mathrm{R}_{\mathrm{gb}}\right)$ 및 정전용량 $\left(\mathrm{C}_{\mathrm{gb}}\right)$ 을 그림 $3(\mathrm{D})$ 에 계산하여 나타내었다. $\mathrm{C}_{\mathrm{gb} 1}$ 은 $2.4 \mathrm{nF}(400 \mathrm{~K})$ 에 서 온도가 높아짐에 따라 $3.2 \mathrm{nF}(560 \mathrm{~K})$ 까지 계속 증 가하다가 이후로는 감소하며, $500 \mathrm{~K}$ 에서 $\mathrm{C}_{\mathrm{gb} 2}$ 로 명확 히 분리되어 $520 \mathrm{~K}$ 에서는 모두 $3.1 \mathrm{nF}$ 의 동일한 값 을 나타내었다(그림 3(B) 참고). 입계 분리 후 $\mathrm{C}_{\mathrm{gb} 2}$ 는 $\mathrm{C}_{\mathrm{gb} 1}$ 보다 빠르게 감소하는 것을 볼 수 있다. 한편 입 계 저항 $\left(\mathrm{R}_{\mathrm{gb}}\right)$ 은 온도 증가에 따라 $\log$ scale로 감소하 

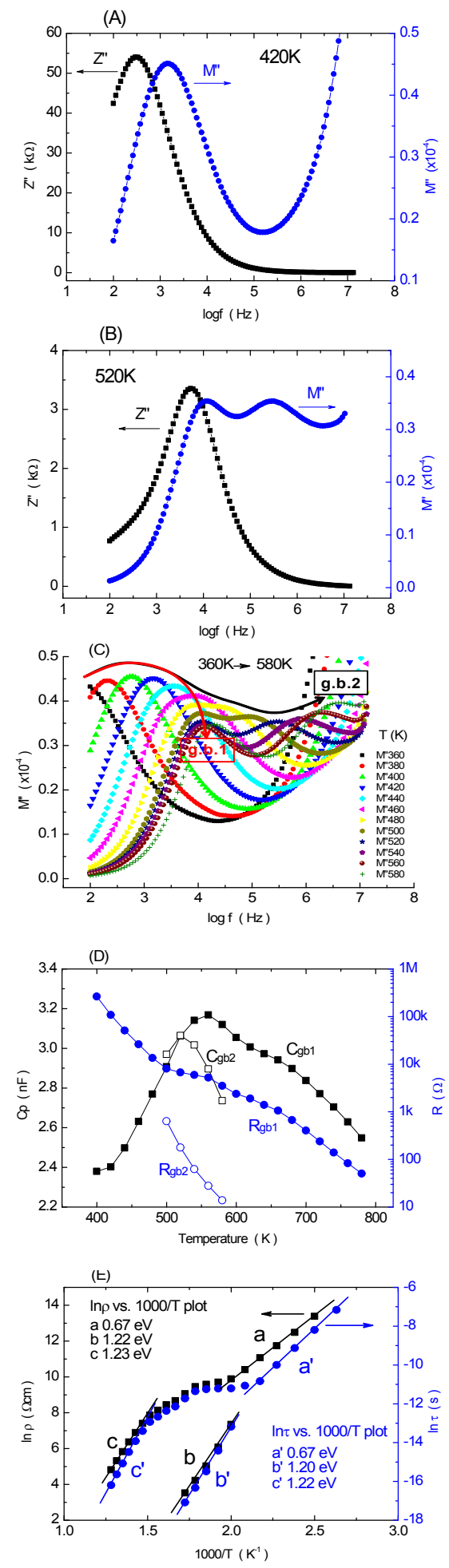

Fig. 3. (A) $Z^{\prime \prime}-$, $M^{\prime \prime}-\log f(420 \mathrm{~K})$, (B) $Z^{\prime \prime}-$, $M^{\prime \prime}-\log f(520$ $\mathrm{K})$, (C) $\mathrm{M}^{\prime \prime}-\operatorname{logf}(360 \sim 580 \mathrm{~K})$, (D) resistance $\left(\mathrm{R}_{\mathrm{gb}}\right)$ and capacitance $\left(\mathrm{C}_{\mathrm{gb}}\right)$ of grain boundaries, (E) $\ln \rho$, $\ln \tau$ vs. 1000/T plot.

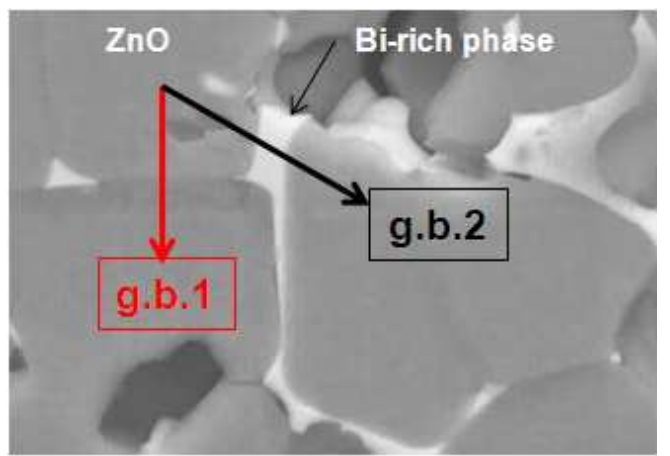

Fig. 4. Schematic diagram of the microstructure and grain boundary assigned by the results of IS \& MS in ZBCr system.

였으며, $520 \mathrm{~K}$ 에서는 $6.7 \mathrm{k} \Omega\left(\mathrm{R}_{\mathrm{gb} 1}\right)$ 과 $0.2 \mathrm{k} \Omega\left(\mathrm{R}_{\mathrm{gb} 2}\right)$ 으로 서로 33 배의 저항값 차이를 나타내면서 점점 더 그 폭이 증가하였다(그림 3(B) 참고).

따라서 입계의 온도에 대한 저항과 정전용량 및 활 성화 에너지를 종합적으로 판단할 때 g.b.1 입계는 바 리스터 특성이 발현되는 주위 산소에 민감하게 반응 하는 $\mathrm{ZnO}-\mathrm{ZnO}$ 계면의 활성 입계(그림 4 참고)로 할 당할 수 있으며, g.b.2 입계는 누설전류와 연관되는 $\mathrm{ZnO}-\mathrm{Bi}_{2} \mathrm{O}_{3}(\mathrm{Cr})-\mathrm{ZnO}$ 계면의 비활성 입계(그림 4 참 고)로 할당할 수 있겠다 $[3,9,10]$.

그림 4 는 그림 3 의 결과들을 토대로 $\mathrm{ZBCr}$ 계 바리 스터의 미세구조에서 g.b.1과 g.b.2 입계를 모식적으 로 제시한 것이다.

\section{4. 결 론}

$\mathrm{ZB}$ 계에 $\mathrm{Cr}_{2} \mathrm{O}_{3}$ 를 $0.5 \mathrm{~mol} \%$ 첨가한 $\mathrm{ZBCr}$ 계에서 나 타나는 결함(트랩)준위와 입계 특성에 대하여 각종 유전함수를 이용하여 분석한 결과 다음과 같은 결론 을 얻었다.

$\mathrm{ZBCr}$ 계에서 발견되는 결함은 유전함수를 이용할 경우 각 함수의 종류에 따라 선택적으로 결함 준위들 이 확인되었으며, 장범위 쿨롱인력에 의한 결함 $(0.11$ $\sim 0.12 \mathrm{eV})$ 과 $Z n_{i}^{*}(0.16 \sim 0.17 \mathrm{eV})$ 및 $V_{o}^{*}(0.33 \mathrm{eV})$ 에 해당하는 3 종류의 결함이 관찰되었다. Admittance spectra에서 나타난 결함 $(0.14 \mathrm{eV}, 0.29 \mathrm{eV})$ 은 각각 장범위 쿨롱인력에 의한 결함과 $V_{o}$ 에 해당됨을 알 수 있었다. 따라서 결함 준위를 분석할 때 사용하는 
각 함수에 따라서 동일한 결함이더라도 각 준위의 크 기는 조금씩 차이를 나타내는 것을 확인하였다. $\mathrm{Cr}$ 이 첨가된 $\mathrm{ZB}$ 계의 입계는 온도가 높아짐에 따라 주위 산소의 흡 - 탈착 반응에 의한 단일 입계 $(0.67 \mathrm{eV})$ 에 서 입계 활성화 에너지가 동일한 이중 입계 $\left(\mathrm{E}_{\mathrm{gb} 1}=1.2\right.$ $\mathrm{eV}, \mathrm{E}_{\mathrm{gb} 2}=1.2 \mathrm{eV}$ )로 분리되는 현상을 나타내었다. 다 양한 유전함수를 이용하여 $\mathrm{ZBCr}$ 계의 입내 및 입계 특성에 대하여 보다 구체적으로 분석할 수 있었으며, 다른 반도성 세라믹스를 분석할 때도 아주 유용한 방 법이 될 것으로 판단된다.

\section{REFERENCES}

[1] L. M. Levinson and H. R. Philipp, Am. Ceram. Soc. Bull. 65, 639 (1986).
[2] T. K. Gupta, J. Am. Ceram. Soc. 73, 1817 (1990).

[3] R. Einzinger, Ann. Rev. Mater. Sci. 17, 299 (1987).

[4] M. Inada and M. Matsuoka, Advances in Ceramics, Vol. 7 (Am. Ceram. Soc., Columbus, OH, 1983) p. 91.

[5] E. Olsson and G. L. Dunlop, J. Appl. Phys. 66, 3666 (1989).

[6] J. Han, P. Q. Mantas, and A. M. R. Senos, J. Euro. Ceram. Soc. 22, 49 (2002).

[7] F. Greuter and G. Blatter, Semicond. Sci. Technol. 5, 111 (1990).

[8] R. Gerhardt, J. Phys. Chem. Solids 55, 1491 (1994).

[9] M. Andres-Verges and A. R. West, J. Electroceram. 1, 125 (1997).

[10] Y.-W. Hong, H.-S. Shin, D.-H. Yeo, J.-H. Kim, and J.-H. Kim, J. KIEEME 21, 738 (2008).

[11] Y.-W Hong, H.-S. Shin, D.-H. Yeo, J.-H. Kim, and J.-H. Kim, J. KIEEME 22, 949 (2009). 